\title{
Human papillomavirus infection in Beijing, People's Republic of China: a population-based study
}

\author{
R Zhao', WY Zhang*,', MH Wu', SW Zhang', J Pan', L Zhu', YP Zhang ${ }^{2}, \mathrm{H} \mathrm{Li}^{3}$, YS Gu and XZ Liu' \\ 'Beijing Obstetric and Gynecology Hospital, Capital Medical University, No. 251 Yao Jiayuan Road, Chaoyang District, Beijing 100026, China; ${ }^{2}$ Beijing \\ Haidian Maternal and Child Health Care Hospital, 35 Hai Diannan Road, Haidian District, Beijing I00080, China; ${ }^{3}$ Beijing Chaoyang Maternal and Child \\ Health Care Hospital, 25 Hua Weili Road, Chaoyang District, Beijing 100020, China; ${ }^{4}$ Beijing Tongzhou Maternal and Child Health Care Hospital, 38 Yu \\ Qiaozhong Road, Tongzhou District, Beijing 101101 , China
}

BACKGROUND: No recent data exist on human papillomavirus (HPV) infection in Beijing, People's Republic of China. MATERIALS AND METHODS: We interviewed and examined a representative, randomly selected sample of 5552 sexually active women aged 25-54 years. Cervical cell samples were analysed for HPV DNA by a MY09/I I-based PCR assay.

RESULTS: Human papillomavirus prevalence was $6.7 \%$ overall and $4.8 \%$ among women without cervical abnormalities. Of the 21 subtypes identified, HPV I 6 was the commonest type (2.6\% overall; $39.1 \%$ of HPV-positive women), followed by HPV 58 (I.0\%), 33 (0.8\%), 43 (0.7\%) and 56 (0.7\%). High-risk HPV types predominated in all age groups. Human papillomavirus prevalence was highest in young to middle-aged women. Marital status, number of husband's sexual partners, age at sexual debut and nulligravidity were all associated with being HPV positive.

CONCLUSIONS: In our survey, HPV I6, HPV 58 and HPV 33 were the most prevalent HPV types in Beijing, indicating the potential for the prophylactic HPV $16 / 18$ vaccine in China.

British Journal of Cancer (2009) I 0 I, I635- 1640. doi:I0.1038/sj.bjc.660535 I www.bjcancer.com

Published online 29 September 2009

(c) 2009 Cancer Research UK

Keywords: human papillomavirus; cervical neoplasia; China; epidemiology

Human papillomavirus (HPV) has been established as a necessary cause of cervical cancer, found in $99.7 \%$ of invasive cervical carcinomas in the best-studied series (Bosch et al, 2002; Woodman et al, 2007). Prevalence of genital HPV infections and type-specific distribution vary greatly by geographical region (Clifford et al, 2005; de Sanjose et al, 2007). Therefore, data on HPV type-specific prevalence among women in different populations are important in elucidating the impact of an HPV vaccine and HPV-based screening in those populations.

The People's Republic of China, with a population of about 1.3 billion, is the world's most populous country. Although Chinese women have been considered to have a relatively low risk (LR) of developing cervical cancer, there are approximately 100000 new cases and 30000 deaths per year in China (Parkin et al, 2002, 2005). In Beijing, the capital of China, the population grew to 15.4 million in 2005, a robust annual increase of $2.1 \%$ (National Bureau of Statistics of China Online, http://www.stats.gov.cn). However, despite representing an appreciable portion of the nation's population, no recent data on HPV prevalence and type-specific distribution exist for Beijing women.

In this study, we report a population-based study of the typespecific and age-specific distribution of cervical HPV infection and of its risk factors in Beijing, China.

*Correspondence: Dr WY Zhang; E-mail: zhangwy9921@hotmail.com Received 22 July 2009; revised 30 August 2009; accepted II September 2009; published online 29 September 2009

\section{MATERIALS AND METHODS}

We carried out the present survey between September 2006 and December 2008 in Beijing, which is the country's political, economic and cultural centre; it consists of 18 districts, four of which are urban, four suburban and 10 outer suburban. A total of 5681 women aged 25-54 years were recruited from the population list of four urban, four suburban and four randomly chosen outer suburban districts in Beijing, China. On the basis of data from the 2005 census published by the National Bureau of Statistics of China, our representative sample of the adult female population of Beijing was stratified by age and regional distribution using a four-stage cluster sampling method. In the first stage, 12 of the 18 districts of Beijing were randomly selected. In the second stage, 4-20 townships were randomly selected from each district according to the proportion of each district's population. Then in the third stage, one neighbourhood was randomly extracted from each township. Finally, from the lists provided by local neighbourhoods, we derived a final random sample of 50 women per neighbourhood. On the basis of the age ratios of the 2005 census, we strove to enroll approximately 10 women aged $25-34$ years, 14 women aged 35-44 years, 13 women aged $45-54$ years and 13 migrant women aged 25-54 years from each neighbourhood.

According to the inclusion criteria, women who (1) lived in Beijing for more than half a year; (2) had no history of cervical surgery; (3) were not pregnant; (4) had no history of pelvic radiation therapy; (5) did not have a gynaecological examination and/or treatment in the past 2 years; and (6) were physically and mentally able to undergo an interview and a pelvic examination 
were invited to participate in this study. After selecting our randomised sample of the population, we made house-to-house visits to recruit these women and invite them to visit their local Maternal and Child Health Hospitals to participate in this study. Here, the interview was administered to the women by two-four experienced gynaecologists, covering socio-demographic information and obstetric and gynaecological history, including number of sexual partners (and also of the husband); participants then had a gynaecological examination and a cervical cell sample taken for HPV DNA analysis.

Written consent was obtained from all participants according to the regulations of the Beijing O\&G hospital and 12 various district Maternal and Child Health Clinics, which approved the study.

A total of 5681 women underwent a pelvic examination; a sample of exfoliated cervical cells for liquid-based cytology and HPV testing was collected later. First, a cytobrush was inserted into the endocervical canal, and rotated gently in a clockwise direction five times. A cytobrush was then inserted into the bottom of a preservation solution vial (Thinprep, CytycCorp, Boxborough, MA, USA) and swirled 10 times vigorously. Finally, the brush was discarded and the vial contents were sent to Beijing O\&G Hospital for cytological analysis. All smears were reported by two cytotechnicians separately, the abnormal/indeterminate ones were reviewed by a senior cytologist for final diagnosis. The results were classified according to the Bethesda System. All women with an abnormal cytological test (ASCUS or more severe) were referred to the study colposcopist and a biopsy was performed. All abnormal smears and $10 \%$ of normal smears chosen at random were sent for review by an experienced cytopathologist. Cervical biopsies were reviewed by a senior pathologist. All confirmed or highly suspicious high-grade or invasive lesions were treated at the Beijing O\&G Hospital with loop excision, surgical conisation, hysterectomy or radiotherapy, according to protocols. In this study, cervical abnormalities were defined as the presence of histologically confirmed cervical intra-epithelial neoplasia (CIN) 1 or worse.

DNA was extracted first from the remainder of the Thinprep sample. To confirm the presence of human DNA, $\beta$-globin PCR analysis was performed on each sample and only $\beta$-globin-positive samples were included in further analyses.

The overall presence of HPV DNA positivity was determined by PCR using 5'-biotinylated MY09/11 consensus primers, as described previously (Coutlee et al, 1999). The presence of 23 subtypes, including HPV $16,18,31,33,35,39,45,51,52,53,56,58$, $59,66,68,73,83, \mathrm{MM} 4,6,11,42,43$ and 44 , was investigated by reverse dot blot hybridisation of the PCR product, as described in previous studies (Kawasaki and Chehab, 1994; Coutlee et al, 1999). High-risk (HR) HPV types for this analysis included HPV types 16, $18,31,33,35,39,45,51,52,56,58,59,68,73$ and 82 (Munoz et al, 2003). All other HPV types were considered LR. Multiple HPV infections with the presence of at least one HR type were considered as HR.

\section{Statistical analysis}

Statistical analysis was performed using SPSS version 15 software. Odds ratios (ORs) for HPV positivity and corresponding 95\% confidence intervals (CIs) were calculated using unconditional, logistic regression, adjusted for age groups $(25-29,30-34,35-39$, 40-44, 45-49 and 50-54 years). The statistical significance of trends for ORs ( $P$ for trend) was assessed by treating ordinal variables as continuous.

\section{RESULTS}

Of the 5681 women who provided cervical cell samples, 32 had inadequate cytology results and 97 had $\beta$-globin-negative samples, leaving 5552 women with valid cytological and HPV results. Among these, $268(4.8 \%)$ had histologically confirmed cervical abnormalities, including $210 \mathrm{CIN} 1,37 \mathrm{CIN} 2,18 \mathrm{CIN} 3$ and 3 microinvasive carcinoma. Meanwhile, HSIL was diagnosed in $0.27 \%(n=15)$ and the proportion of HSIL that was histologically confirmed was $93.3 \%$. The mean age of the total screened population was 39.7 years.

Overall, the prevalence of HPV of any subtype was $6.7 \%$ (4.8 and $44.4 \%$ among women with normal and abnormal cervical findings, respectively, Table 1). A total of 229 women (4.1\% overall, $61.7 \%$ of HPV-positive women) had single-type infection and a total of 142 women $(2.6 \%, 38.3 \%)$ had multiple HPV infections. In all, 21 individual types were identified. High-risk HPV infections were more frequent (5.8\% of all women) than LR infections $(2.0 \%)$. The most commonly found types in either single or multiple infections were HPV 16 (HR) (2.6\%), HPV 58 (HR) (1.0\%), HPV 33 (HR) (0.8\%), HPV 43 (0.7\%) (an LR type, 41 women) and HPV 56 (HR) $(0.7 \%)$. High-risk HPV was found in $38.8 \%$ of women with cervical abnormalities, and in only $4.1 \%$ of normal women. The proportion of HPV 16 and HPV 18, both of which are included in currently licensed prophylactic HPV vaccines, was $45.8 \%$ among HPVpositive women and their prevalence was $85.7 \%$ for pathological grades of CIN 3 or worse.

Figure 1 shows the age distribution of HPV prevalence (any type, HR and LR types separately). Age-specific prevalence increased from $4.9 \%$ at age $25-29$ years to a peak of $8.2 \%$ at age $30-34$ years and then decreased to $7.1 \%$ at age $35-39$ years. Among women aged 40-54 years, prevalence decreased progressively from $7.5 \%$ at $40-44$ years to 6.4 and $4.9 \%$ at ages $45-49$ and 50-54 years, respectively. Age-specific prevalence in Beijing peaked at $8.2 \%$ at $30-34$ years. High-risk types were common in women aged 30-34 years, and then gradually decreased. In contrast, for LR prevalence, there was no significant age-specific trend. The proportion of HPV-positive samples infected with only one HPV type was highest at 30-34 years, whereas the proportions with multiple types at 30-34- and 40-44-year age groups were 3.0 and $3.1 \%$, respectively, which were higher than other age groups (Figure 2).

Table 2 show the relationship between HPV positivity and some major characteristics of this population after adjustment for age. Smoking women were associated with a higher HPV prevalence than were never smokers $(\mathrm{OR}=1.25,95 \%$ CI: $1.01-1.56)$. Unmarried women were more likely to be infected with HR $(\mathrm{OR}=1.63$, 95\% CI: $1.07-2.49)$ and LR HPV (OR $=1.54,95 \% \mathrm{CI}$ : 0.77-3.09) than married women. Most women (96.9\%) reported having only one sexual partner in their life; those with two or more lifetime sexual partners seemed to have an increased risk of HR HPV positivity (OR $=1.45,95 \%$ CI: $1.06-2.41)$. The prevalence of HPV was significantly increased with the number of husband's sexual partners (OR for two partners $v s$ one $=1.66$, 95\% CI: 1.07-2.57; OR for three partners or more $v s$ one $=3.67$, 95\% CI: $0.77-17.43)$. The increasing age at first intercourse was inversely associated with being HPV positive (OR for $\leqslant 20 \mathrm{vs}$ $\geqslant 28$ years $=1.74,95 \%$ CI: $1.14-2.65$; OR for $21-27 v s \geqslant 28$ years $=1.10,95 \%$ CI: $0.84-1.46$ )

Nulliparous women were more likely to be infected with HR HPV than women who had been pregnant earlier $(\mathrm{OR}=2.15,95 \%$ CI: 1.16-4.00). However, there was no association of birth numbers with HPV positivity (data not shown). Age at first pregnancy was unrelated to HPV infection, whereas a trend of increased HPV positivity with younger age at first pregnancy was seen $(\mathrm{OR}$ for $\leqslant 24 v s \geqslant 30$ years $=2.09,95 \% \mathrm{CI}$ : $1.01-4.32$; OR for $25-29 v s \geqslant 30$ years $=2.00,95 \%$ CI: $0.97-4.12$ ). Oral contraceptive use was not associated with HR and LR HPV infections, but condom use was somewhat protective against HPV infection. No significant association was found between HPV positivity and race, occupation, education level, age at menarche, marriage or menopause, or history of spontaneous or voluntary abortion (data 
Table I Prevalence of various human papillomavirus (HPV) types by histological findings among 5552 women (Beijing, China, 2008)

\begin{tabular}{|c|c|c|c|c|c|c|c|c|c|}
\hline HPV type ${ }^{a}$ & \multicolumn{9}{|c|}{ Cervical abnormalities } \\
\hline Negative & & & $5032(95.2)$ & & & $149(56.0)$ & - & - & $5|8|(93.3)$ \\
\hline \multicolumn{10}{|l|}{ Positive } \\
\hline Low risk & 35 & 43 & $78(1.5)$ & 13 & 20 & $33(12.3)$ & 48 & 63 & || $\mid(2.0)$ \\
\hline \multicolumn{10}{|l|}{ High risk } \\
\hline 16 & 51 & 37 & $88(1.7)$ & 30 & 27 & $57(21.3)$ & 81 & 64 & $145(2.6)$ \\
\hline 58 & 20 & 22 & $42(0.8)$ & 5 & 7 & $12(4.5)$ & 25 & 29 & $54(1.0)$ \\
\hline 33 & 6 & 26 & $32(0.6)$ & 2 & 13 & $15(5.6)$ & 8 & 39 & $47(0.8)$ \\
\hline 56 & 11 & 18 & $29(0.5)$ & 3 & 7 & $10(3.7)$ & 14 & 25 & $39(0.7)$ \\
\hline 51 & 5 & 3 & $8(0.2)$ & 2 & 2 & $4(1.5)$ & 7 & 5 & $12(0.2)$ \\
\hline 39 & 2 & 0 & $2(0.03)$ & 3 & 2 & $5(1.9)$ & 5 & 2 & $7(0.1)$ \\
\hline 45 & 2 & 2 & $4(0.1)$ & I & I & $2(0.8)$ & 3 & 3 & $6(0.1)$ \\
\hline 73 & 0 & 4 & $4(0.1)$ & 0 & 0 & 0 & 0 & 4 & $4(0.1)$ \\
\hline 52 & 0 & I & I (0.02) & 0 & 0 & 0 & 0 & i & I $(0.02)$ \\
\hline \multicolumn{10}{|l|}{ Low risk } \\
\hline 43 & 8 & 19 & $27(0.5)$ & 5 & 9 & $14(5.2)$ & 13 & 28 & $4 \mid(0.7)$ \\
\hline 66 & 13 & 12 & $25(0.5)$ & 5 & 7 & $12(4.5)$ & 18 & 19 & $37(0.7)$ \\
\hline 42 & 4 & 7 & $11(0.2)$ & 0 & 3 & $3(1.1)$ & 4 & 10 & $14(0.3)$ \\
\hline 53 & 3 & 6 & $9(0.2)$ & 2 & 2 & $4(1.5)$ & 5 & 8 & $13(0.2)$ \\
\hline 11 & 4 & I & $5(0.1)$ & 0 & I & I $(0.4)$ & 4 & 2 & $6(0.1)$ \\
\hline 83 & 3 & 2 & $5(0.1)$ & 0 & 0 & 0 & 3 & 2 & $5(0.1)$ \\
\hline
\end{tabular}

The same women can be counted more than once for multiple infection. ' Includes all histologically confirmed CINI and worse.

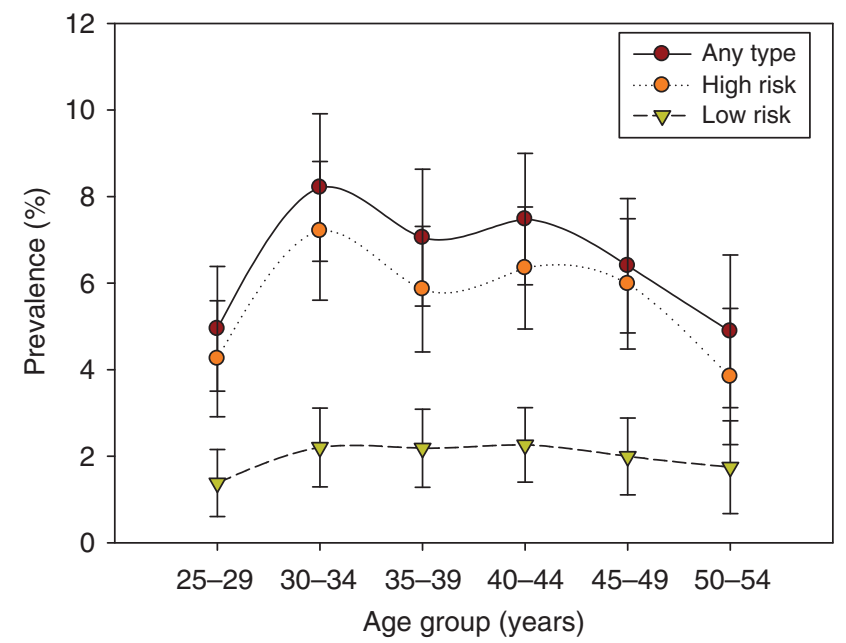

Figure I Age-specific prevalence of human papillomavirus DNA and corresponding 95\% confidence interval (Beijing, China, 2008).

not show). In addition to age, when marital status, number of sexual partners, husband's sexual partners and smoking were included in the same multiple logistic regression, the corresponding ORs did not change materially.

Figure 3 shows the percentage of specific HPV types in different pathological grades. There was an obvious increasing percentage

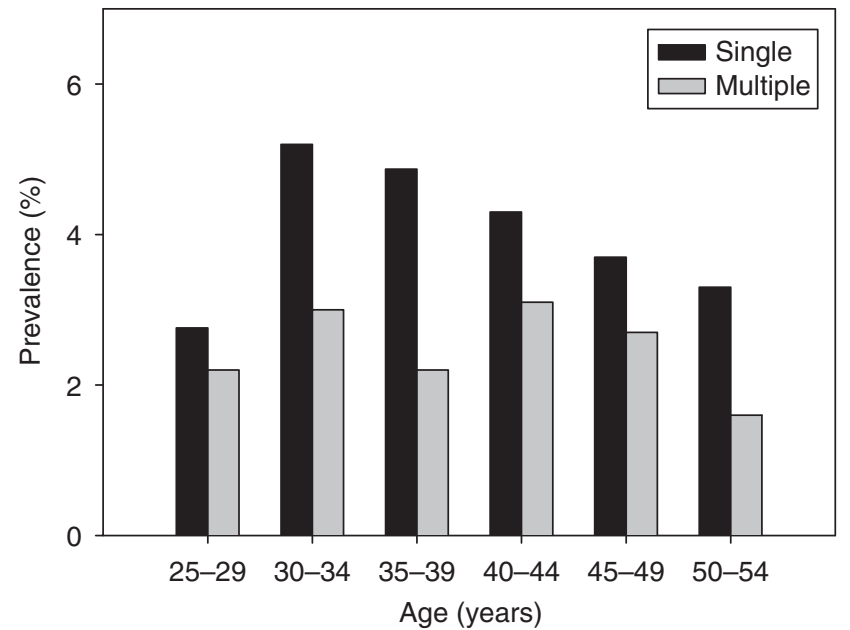

Figure 2 Percentage of women in each age group infected with single and multiple human papillomavirus.

with increasing pathology for HPV 16 and the highest percentage was in samples worse than CIN3. For HPV 18, the highest prevalence was also seen in samples worse than CIN3. For HPV types 35,58 and 68 , the highest proportion was observed in the normal group, and for HPV types 33, 43, 56 and 66, it was observed in the CIN1 group. 
Table 2 Detection of cervical human papillomavirus (HPV) DNA according to major risk factors among 5552 women (Beijing, China, 2008)

\begin{tabular}{|c|c|c|c|}
\hline & \multirow[b]{2}{*}{ Total no. } & \multirow{2}{*}{$\frac{\text { HPV DNA positive }}{\text { Number (\%) }}$} & \multirow[b]{2}{*}{$O R^{a}(95 \% \mathrm{Cl})$} \\
\hline & & & \\
\hline \multicolumn{4}{|l|}{ Age (years) } \\
\hline $25-29^{b}$ & 870 & $43(4.9)$ & I \\
\hline $30-34$ & 999 & $82(8.2)$ & $1.72(1.18-2.52)$ \\
\hline $35-39$ & 1007 & $71(7.1)$ & $1.46(0.99-2.16)$ \\
\hline $40-44$ & 1150 & $86(7.5)$ & $1.56(1.07-2.27)$ \\
\hline $45-49$ & 953 & $61(6.4)$ & $1.32(0.88-1.97)$ \\
\hline $50-54$ & 573 & $28(4.9)$ & $0.99(0.61-1.61)$ \\
\hline$P$ for trend & & & 0.031 \\
\hline \multicolumn{4}{|l|}{ Smoking } \\
\hline Ever & 3285 & $238(7.2)$ & $1.25(1.01-1.56)$ \\
\hline Never $^{b}$ & 2266 & $133(5.9)$ & । \\
\hline \multicolumn{4}{|l|}{ Marital status } \\
\hline Married ${ }^{b}$ & 5257 & $343(6.5)$ & 1 \\
\hline Unmarried $^{c}$ & 295 & $28(9.5)$ & $1.49(0.99-2.25)$ \\
\hline \multicolumn{4}{|c|}{ Lifetime sexual partners } \\
\hline $1^{\mathrm{b}}$ & 5378 & $358(6.7)$ & । \\
\hline$\geqslant 2$ & 168 & $13(7.7)$ & $1.24(0.64-2.04)$ \\
\hline \multicolumn{4}{|c|}{ Husband sex partners } \\
\hline $1^{\mathrm{b}}$ & 5270 & $338(6.4)$ & I \\
\hline 2 & 231 & $24(10.4)$ & $1.66(1.07-2.57)$ \\
\hline$\geqslant 3$ & 10 & $2(20.0)$ & $3.67(0.77-17.43)$ \\
\hline$P$ for trend & & & 0.021 \\
\hline \multicolumn{4}{|c|}{ Age at first intercourse (years) } \\
\hline$\leqslant 20$ & 379 & $38(10.0)$ & $1.74(1.14-2.65)$ \\
\hline $21-27$ & 3939 & $261(6.6)$ & $1.10(0.84-1.46)$ \\
\hline$\geqslant 28^{b}$ & 1226 & $72(5.9)$ & | \\
\hline$P$ for trend & & & 0.027 \\
\hline \multicolumn{4}{|l|}{ Pregnant } \\
\hline Never & 113 & $12(10.6)$ & $1.82(0.98-3.37)$ \\
\hline Ever $^{\mathrm{b}}$ & 5438 & $359(6.6)$ & । \\
\hline \multicolumn{4}{|c|}{ Age at first pregnancy (years) } \\
\hline$\leqslant 24$ & 2613 & $182(7.0)$ & $2.09(1.01-4.32)$ \\
\hline $25-29$ & 2593 & $169(6.5)$ & $2.00(0.97-4.12)$ \\
\hline$\geqslant 30^{b}$ & 227 & $8(3.5)$ & 1 \\
\hline$P$ for trend & & & 0.135 \\
\hline \multicolumn{4}{|c|}{ Oral contraceptives } \\
\hline Never ${ }^{\mathrm{b}}$ & 191 & $16(8.4)$ & I \\
\hline Ever & 5361 & $355(6.6)$ & $0.75(0.39-1.43)$ \\
\hline \multicolumn{4}{|l|}{ Condom use } \\
\hline Never ${ }^{b}$ & 3525 & $251(7.1)$ & 1 \\
\hline Ever & 2027 & $120(5.9)$ & $0.8(0.63-0.96)$ \\
\hline
\end{tabular}

Abbreviations: $\mathrm{OR}=$ odds ratio; $\mathrm{Cl}=$ confidence interval. ${ }^{\mathrm{a}}$ Adjusted for age. ${ }^{\mathrm{b}}$ Reference category. ${ }^{\mathrm{C}}$ Unmarried includes separated, divorced and widowed.

\section{DISCUSSION}

Among this representative sample of Beijing women, HPV 16 was the most frequently detected type, as found in many previous studies in different world regions (Clifford et al, 2005). Nevertheless, its overall prevalence was relatively low (6.7\%), which correlates with the low incidence of cervical cancer in China (Yang et al, 2003). Meanwhile, a large proportion of women with only one sexual partner $(96.9 \%)$ in this general population was probably an important cause of low HPV prevalence in Beijing. In previous Asian studies, HPV prevalence was lower, such as in Vietnam (Hanoi, 2.0\%; Pham et al, 2003), Thailand (Lampang, 9.1\%;

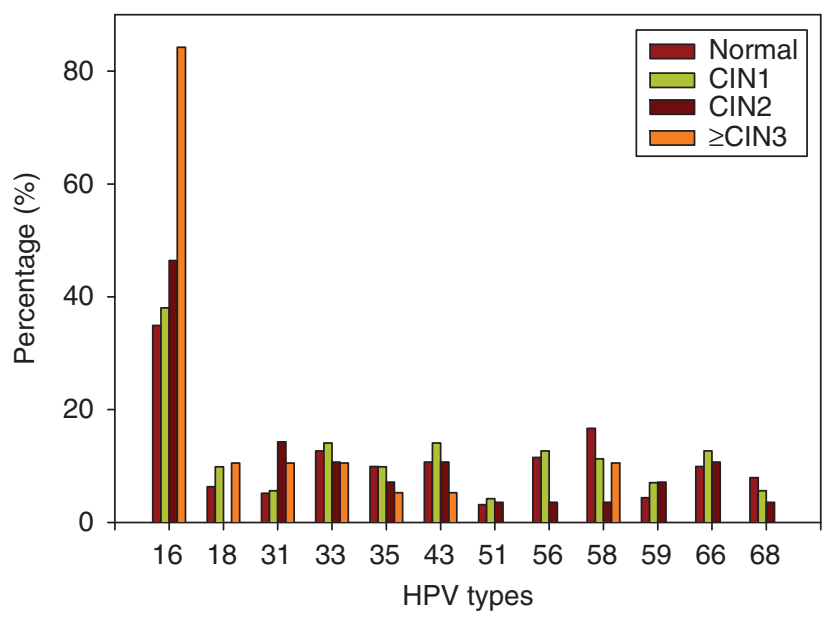

Figure 3 Human papillomavirus type-specific distribution and pathology grade (Beijing, China, 2008).

Sukvirach et al, 2003) and Indonesia (11.4\%; Vet et al, 2008), compared with countries such as Nigeria (Ibadan, 26.3\%; Thomas et al, 2004) and Chile (29.2\%; Ferreccio et al, 2008).

Besides HPV 16, HR HPV 58 and 33 were also common in this general population, followed by LR HPV 43 and HR HPV 56. Surveys have reported relatively high HPV 58 and HPV 33 prevalence in Asia (de Sanjose et al, 2007). HPV 16, 18, 58, 33, 52 and 45 were commoner in Asia than in other areas (Bao et al, 2008b). The predominance of HPV 58 and HPV 33 in Beijing is in accordance with the results of certain surveys in other regions of China (Dai et al, 2006; Li et al, 2006; Bao et al, 2008a).

In our survey, HPV prevalence was highest in women aged $30-$ 34 years and declined thereafter. This age-specific pattern is similar to some previous studies in China (Dai et al, 2006), but differs somewhat from other surveys elsewhere (Munoz et al, 2004; Hibbitts et al, 2006). In China, which is a relatively conservative society, late marriage and late childbirth are encouraged. The relatively late age at first intercourse (mean: 24.0 years), along with a tendency to delay marriage and childbirth, may explain the relatively high HPV prevalence in young to middle-aged women in Beijing. Furthermore, persistent infections are reported to gradually become more prominent with age (Castle et al, 2005). In our survey, the prevalence of multiple HPV infection is high in women aged 30-34 years. Thus, the high HPV prevalence in young to middle-aged women in Beijing may indicate a relative lack of viral clearance or a reactivation of latent infection, which formed co-infection.

The number of husband's sexual partners was strongly associated with HPV infection, indicating the important role of males in HPV transmission to female partners in the Beijing population, among whom the majority $(96.9 \%)$ have only one sexual partner in their life. As expected, marital status of women and age at first intercourse were risk factors for HPV infection. Similar to previous studies (Deacon et al, 2000; Munoz et al, 2002; Pham et al, 2003; Shin et al, 2003), we found that nulliparous women had a higher prevalence of HPV than women who had been pregnant earlier. However, there was no trend with the number of pregnancies, as found in some studies (Thomas et al, 2004). We found an association between smoking and HPV prevalence as in many other (Sukvirach et al, 2003; Vaccarella et al, 2008), though not all, studies (Harris et al, 2004). The use of oral contraceptives was not associated with HPV infection in our study, but we had no details of duration of use; at present, the question of an association is unclear (Green et al, 2003). Previous findings are also inconsistent for the association between condom use and HPV infection (Manhart and Koutsky, 2002; Vaccarella et al, 2006); our data indicated a possible limited protective trend. 
Comparisons of the distribution of common HPV types among pathological grades, HPV 16 and HPV 18 were frequent with CIN3/ $\mathrm{CC}$ relative to their prevalence in normal, CIN1 and CIN2 grades, reflecting their predominant roles in invasive carcinomas in Beijing. In most countries, HPV 16 is by far the most common type in cervical carcinoma, followed by HPV 18 (Bosch et al, 2008; Zhao et al, 2008; Cai et al, 2009). It would seem that the prophylactic vaccine against HPV 16/18 will also be effective in reducing the cervical cancer burden in Beijing, as the prevalence of these two types was $85.7 \%$ for pathological grades of CIN 3 or worse.

In conclusion, the commonest HPV types in the general female population of Beijing are HPV 16, 58 and 33, and the HPV 16/18 vaccination is expected to substantially reduce the cervical cancer burden in China.

\section{ACKNOWLEDGEMENTS}

This study was funded by the Beijing Municipal Science and Technology commission (D0906008040491), and it was a collaborative project among the Beijing Obstetrics and Gynecology Hospital (Beijing O\&G Hospital), Haidian Maternal and Child Health Care Hospital, Chaoyang Maternal and Child Health Care Hospital, Tongzhou Maternal and Child Health Care Hospital, Dongcheng Maternal and Child Health Care Hospital, Fengtai Maternal and Child Health Care Hospital, Huairou Maternal and Child Health Care Hospital, Yanqing Maternal and Child Health Care Hospital, Daxing Maternal and Child Health Care Hospital, Xicheng Maternal and Child Health Care Hospital, Shijingshan Maternal and Child Health Care Hospital, Chongwen Maternal and Child Health Care Hospital and Xuanwu Maternal and Child Health Care Hospital as well as among 12 various district Maternal and Child Health Clinics. We gratefully acknowledge the collaboration of the whole research staff and nurses at Beijing O\&G Hospital and at 12 various district Maternal and Child Health Clinics who participated in sample handling. Ms Z Xie, Ms J Fen and Mr JD Wang helped with the data entry work. We also thank Ms H Stoklosa for modifying the paper.

\section{REFERENCES}

Bao YP, Li N, Smith JS, Qiao YL (2008a) Human papillomavirus typedistribution in the cervix of Chinese women: a meta-analysis. Int J STD AIDS 19: $106-111$

Bao YP, Li N, Smith JS, Qiao YL (2008b) Human papillomavirus type distribution in women from Asia: a meta-analysis. Int J Gynecol Cancer 18: $71-79$

Bosch FX, Burchell AN, Schiffman M, Giuliano AR, de Sanjose S, Bruni L, Tortolero-Luna G, Kjaer SK, Munoz N (2008) Epidemiology and natural history of human papillomavirus infections and type-specific implications in cervical neoplasia. Vaccine 26(Suppl 10): K1-K16

Bosch FX, Lorincz A, Munoz N, Meijer CJ, Shah KV (2002) The causal relation between human papillomavirus and cervical cancer. J Clin Pathol 55: 244-265

Cai HB, Ding XH, Chen CC (2009) Prevalence of single and multiple human papillomavirus types in cervical cancer and precursor lesions in Hubei, China. Oncology 76: $157-161$

Castle PE, Schiffman M, Herrero R, Hildesheim A, Rodriguez AC, Bratti MC, Sherman ME, Wacholder S, Tarone R, Burk RD (2005) A prospective study of age trends in cervical human papillomavirus acquisition and persistence in Guanacaste, Costa Rica. J Infect Dis 191: $1808-1816$

Clifford GM, Gallus S, Herrero R, Munoz N, Snijders PJ, Vaccarella S, Anh PT, Ferreccio C, Hieu NT, Matos E, Molano M, Rajkumar R, Ronco G, de Sanjose S, Shin HR, Sukvirach S, Thomas JO, Tunsakul S, Meijer CJ, Franceschi S (2005) Worldwide distribution of human papillomavirus types in cytologically normal women in the International Agency for Research on Cancer HPV prevalence surveys: a pooled analysis. Lancet 366: $991-998$

Coutlee F, Gravitt P, Richardson H, Hankins C, Franco E, Lapointe N, Voyer H (1999) Nonisotopic detection and typing of human papillomavirus DNA in genital samples by the line blot assay. The Canadian Women's HIV study group. J Clin Microbiol 37: $1852-1857$

Dai M, Bao YP, Li N, Clifford GM, Vaccarella S, Snijders PJ, Huang RD, Sun LX, Meijer CJ, Qiao YL, Franceschi S (2006) Human papillomavirus infection in Shanxi Province, People's Republic of China: a populationbased study. Br J Cancer 95: 96-101

de Sanjose S, Diaz M, Castellsague X, Clifford G, Bruni L, Munoz N, Bosch FX (2007) Worldwide prevalence and genotype distribution of cervical human papillomavirus DNA in women with normal cytology: a metaanalysis. Lancet Infect Dis 7: 453-459

Deacon JM, Evans CD, Yule R, Desai M, Binns W, Taylor C, Peto J (2000) Sexual behaviour and smoking as determinants of cervical HPV infection and of CIN3 among those infected: a case-control study nested within the Manchester cohort. Br J Cancer 83: 1565-1572

Ferreccio C, Corvalan A, Margozzini P, Viviani P, Gonzalez C, Aguilera X, Gravitt PE (2008) Baseline assessment of prevalence and geographical distribution of HPV types in Chile using self-collected vaginal samples. BMC Public Health 8: 78
Green J, Berrington de Gonzalez A, Smith JS, Franceschi S, Appleby P, Plummer M, Beral V (2003) Human papillomavirus infection and use of oral contraceptives. $\mathrm{Br}$ J Cancer 88: $1713-1720$

Harris TG, Kulasingam SL, Kiviat NB, Mao C, Agoff SN, Feng Q, Koutsky LA (2004) Cigarette smoking, oncogenic human papillomavirus, Ki-67 antigen, and cervical intraepithelial neoplasia. Am J Epidemiol 159: $834-842$

Hibbitts S, Rieck GC, Hart K, Powell NG, Beukenholdt R, Dallimore N, McRea J, Hauke A, Tristram A, Fiander AN (2006) Human papillomavirus infection: an anonymous prevalence study in South Wales, UK. Br J Cancer 95: 226-232

Kawasaki ES, Chehab FF (1994) Analysis of gene sequences by hybridization of PCR-amplified DNA to covalently bound oligonucleotide probes. The reverse dot blot method. Methods Mol Biol 28: $225-236$,

Li LK, Dai M, Clifford GM, Yao WQ, Arslan A, Li N, Shi JF, Snijders PJ, Meijer CJ, Qiao YL, Franceschi S (2006) Human papillomavirus infection in Shenyang City, People's Republic of China: a population-based study. Br J Cancer 95: $1593-1597$

Manhart LE, Koutsky LA (2002) Do condoms prevent genital HPV infection, external genital warts, or cervical neoplasia? A meta-analysis. Sex Transm Dis 29: $725-735$

Munoz N, Bosch FX, de Sanjose S, Herrero R, Castellsague X, Shah KV, Snijders PJ, Meijer CJ (2003) Epidemiologic classification of human papillomavirus types associated with cervical cancer. N Engl J Med 348: $518-527$

Munoz N, Franceschi S, Bosetti C, Moreno V, Herrero R, Smith JS, Shah KV, Meijer CJ, Bosch FX (2002) Role of parity and human papillomavirus in cervical cancer: the IARC multicentric case-control study. Lancet 359: $1093-1101$

Munoz N, Mendez F, Posso H, Molano M, van den Brule AJ, Ronderos M, Meijer C, Munoz A (2004) Incidence, duration, and determinants of cervical human papillomavirus infection in a cohort of Colombian women with normal cytological results. J Infect Dis 190: 2077-2087

Parkin DM, Bray F, Ferlay J, Pisani P (2005) Global cancer statistics, 2002. CA Cancer J Clin 55: 74-108

Parkin DM, Whelan SL, Ferlay J, Thomas DB, Teppo L (2002) Cancer Incidence in Five Continents, Volume VIII. IARC Sci Publ No. 155 IARC Press: Lyon

Pham TH, Nguyen TH, Herrero R, Vaccarella S, Smith JS, Nguyen Thuy TT, Nguyen HN, Nguyen BD, Ashley R, Snijders PJ, Meijer CJ, Munoz N, Parkin DM, Franceschi S (2003) Human papillomavirus infection among women in South and North Vietnam. Int J Cancer 104: 213-220

Shin HR, Lee DH, Herrero R, Smith JS, Vaccarella S, Hong SH, Jung KY, Kim HH, Park UD, Cha HS, Park S, Touze A, Munoz N, Snijders PJ, Meijer CJ, Coursaget P, Franceschi S (2003) Prevalence of human papillomavirus infection in women in Busan, South Korea. Int J Cancer 103: $413-421$ 
Sukvirach S, Smith JS, Tunsakul S, Munoz N, Kesararat V, Opasatian O, Chichareon S, Kaenploy V, Ashley R, Meijer CJ, Snijders PJ, Coursaget P, Franceschi S, Herrero R (2003) Population-based human papillomavirus prevalence in Lampang and Songkla, Thailand. $J$ Infect Dis 187: $1246-1256$

Thomas JO, Herrero R, Omigbodun AA, Ojemakinde K, Ajayi IO, Fawole A, Oladepo O, Smith JS, Arslan A, Munoz N, Snijders PJ, Meijer CJ, Franceschi S (2004) Prevalence of papillomavirus infection in women in Ibadan, Nigeria: a population-based study. Br J Cancer 90: $638-645$

Vaccarella S, Franceschi S, Herrero R, Munoz N, Snijders PJ, Clifford GM, Smith JS, Lazcano-Ponce E, Sukvirach S, Shin HR, de Sanjose S, Molano M, Matos E, Ferreccio C, Anh PT, Thomas JO, Meijer CJ (2006) Sexual behavior, condom use, and human papillomavirus: pooled analysis of the IARC human papillomavirus prevalence surveys. Cancer Epidemiol Biomarkers Prev 15: 326-333
Vaccarella S, Herrero R, Snijders PJ, Dai M, Thomas JO, Hieu NT, Ferreccio C, Matos E, Posso H, de Sanjose S, Shin HR, Sukvirach S, Lazcano-Ponce E, Munoz N, Meijer CJ, Franceschi S (2008) Smoking and human papillomavirus infection: pooled analysis of the International Agency for Research on Cancer HPV Prevalence Surveys. Int J Epidemiol 37: 536-546

Vet JN, de Boer MA, van den Akker BE, Siregar B, Lisnawati, Budiningsih S, Tyasmorowati D, Moestikaningsih, Cornain S, Peters AA, Fleuren GJ (2008) Prevalence of human papillomavirus in Indonesia: a populationbased study in three regions. Br J Cancer 99: 214-218

Woodman CB, Collins SI, Young LS (2007) The natural history of cervical HPV infection: unresolved issues. Nat Rev Cancer 7: 11-22

Yang L, Parkin DM, Li L, Chen Y (2003) Time trends in cancer mortality in China: 1987-1999. Int J Cancer 106: $771-783$

Zhao Y, Lin H, Shen D, Xuan Y, Lin Z (2008) Distribution of HPV genotypes in uterine cervical lesions in Yanbian, northern China. Pathol Int 58: $643-647$ 